\title{
Separation of Transformers for Class 1E Systems in Nuclear Power Plants
}

\author{
Sang-Hyun Lee and Choong-Koo Chang \\ Nuclear Power Plant Engineering Department, KEPCO International Nuclear Graduate School, 658-91 Haemaji-ro, \\ Seosang-myeon, Ulju-gun, Ulsan 45014, Republic of Korea \\ Correspondence should be addressed to Sang-Hyun Lee; wing088@naver.com
}

Received 2 September 2016; Revised 18 November 2016; Accepted 4 December 2016; Published 2 January 2017

Academic Editor: Arkady Serikov

Copyright (C) 2017 S.-H. Lee and C.-K. Chang. This is an open access article distributed under the Creative Commons Attribution License, which permits unrestricted use, distribution, and reproduction in any medium, provided the original work is properly cited.

In order to supply electric power to the safety related loads, safety and reliability of onsite power have to be ensured for the safety function performance in nuclear power plants. Even though the existing electric power system of APR1400 meets the requirements of codes regarding Class $1 \mathrm{E}$ system, there is a room for improvement in the design margin against the voltage drop and short circuit current. This paper discusses the amount that the voltage drop and short circuit current occur in the existing electric power system of APR1400. Additionally, this paper studies with regard to the improved model that has the extra margin against the high voltage drop and short circuit current by separation of unit auxiliary transformer (UAT) and standby auxiliary transformer (SAT) for the Class $1 E$ loads. The improved model of the electric power system by separation of UAT and SAT has been suggested through this paper. Additionally, effects of reliability and cost caused by the electric power system modification are considered.

\section{Introduction}

In order to enhance safety and reliability of Class $1 \mathrm{E}$ system [1] against the abnormal conditions such as high short circuit current and voltage drop in nuclear power plant, it is worthwhile analyzing the existing electric power system. Based on the analyzed result, the vulnerability of the electric power system which has insufficient design margin and the improvable point for the reliability will be defined. In this paper UAT and SAT separation is discussed as one method to improve the vulnerability and reliability of electric power system in nuclear power plants.

There is much study in recent years regarding improvement of the transformer itself [2-7]. Even if the reliability of the power transformers is significantly important for the safety system in nuclear power plants, the reports are focused on specific power transformer improvement itself. In addition, the electric power system of APR1400 is demonstrated generally in another study paper [8]. Through the paper general description and review were demonstrated for the electric power system of APR1400. Moreover, the simulation and analysis of the electric power system in Korea were introduced through another paper [9]. In the paper, the research methodology of simulation and analysis were described for current electric power system.

By contrast, the present paper discusses the current vulnerability and points that can be improved in the existing electric power system and, moreover, suggests an improved electric power system model for APR1400. Additionally, the reliability was considered. The vulnerability of the existing electric power system will be defined by the load flow and short circuit current analysis through an electrical transient analysis program (ETAP). Based on the determined vulnerability through ETAP analysis, the improved and modified electric power system model will be suggested through this paper. Furthermore, the present paper shows the amount that the design margin has increased by the separation of UAT and SAT.

For the accurate analysis, the real load profile in accordance with each loading category is necessary. Moreover, improved safety and reliability of the electric power system in nuclear power plants have been found in this paper. For a more exact analysis, typical APR1400 data was applied.

\section{Electric Power System of APR1400}

The electric power systems in nuclear power plants receive power from offsite power via the two preferred power supply 


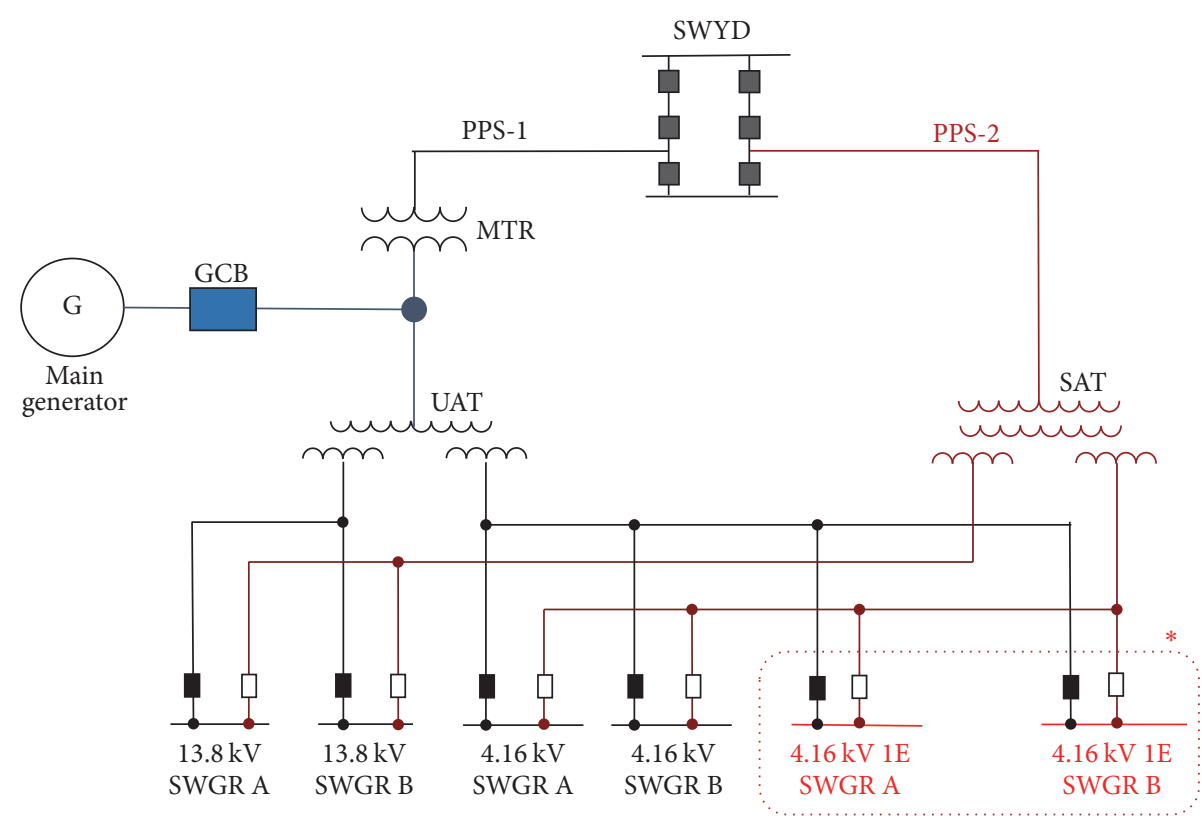

FIGURE 1: The existing electric power system of APR1400. * This dotted line represents the boundary of Class $1 \mathrm{E}$ system. Otherwise, out of the dotted line is represented non-Class $1 \mathrm{E}$ system.

(PPS) lines. The power flows to the Class $1 \mathrm{E}$ and non-Class $1 \mathrm{E}$ simultaneously through the UAT or SAT (see Figure 1). NonClass $1 \mathrm{E}$ Bus (13.8 kV Switchgear and $4.16 \mathrm{kV}$ Switchgear) distributes power to the nonsafety function loads. Similarly, Class $1 \mathrm{E}$ Bus (4.16 kV Switchgear) supplies power to the safety function loads as shown in Figure 1.

2.1. Applicable Codes and Requirements. The electric power system of APR1400 totally meets the requirements of "General Design Criteria (10CFR50, Appendix A) Criterion 17, Electric power systems" [10].

According to the code, the electric power from the transmission network to the onsite electric distribution system shall be supplied by two physically independent circuits (not necessarily on separate rights of way) designed and located so as to minimize to the extent practically the likelihood of their simultaneous failure under operating and postulated accident and environmental conditions.

2.2. The Vulnerability of the Existing Electric Power System. In order to find the vulnerability of the existing electric power system, load flow and short circuit current analysis of the existing electric power system were simulated first. For the conservative approach, the most severe condition was considered among five (5) loading categories as follows.

(1) Plant start-up (Cat. I).

(2) Normal operation (Cat. II).

(3) Loss of coolant accident (LOCA) condition (Cat. III).

(4) Hot standby condition (Cat. IV).

(5) Emergency diesel generator (EDG) test during the normal operation (Cat. V).
Through the load flow analysis, the most severe voltage drop was shown on the $4.16 \mathrm{kV}$ Class $1 \mathrm{E}$ Bus A and $4.16 \mathrm{kV}$ non-Class $1 \mathrm{E}$ Bus B as $4.55 \%$ of the nominal voltage during the plant start-up condition (Cat. I) as shown in Figure 2.

Even though UAT and SAT have on-load tap changers (OLTC), the voltage varies from $95.45 \%$ to $103.21 \%$, which depends on the loading categories due to the high percent impedance of UAT and SAT (i.e., $Z_{\mathrm{HY}}$ of UAT $=36 \%, Z_{\mathrm{HY}}$ of SAT $=38 \%$ ) as shown in Table 1 .

The voltage drop from UAT or SAT to the downstream loads should be limited within a certain range even during the severe condition. The degraded undervoltage relay, which actuates EDG in the case of the loss of power condition, is set about to $95 \%$ of the $4.16 \mathrm{kV}$ bus nominal voltage corresponding to $90 \%$ of $480 \mathrm{~V}$ motor control center (MCC) voltage. During the severe condition, the design margin has only $0.45 \%(=95.45 \%-95 \%)$. Because of the insufficient design margin, big size cables were installed for the downstream loads to reduce the voltage drop in the existing electric power system.

On the other hand, the most severe short circuit current occurs during the normal operation with EDG test caused by the current contribution from EDG. Through the short circuit current analysis, the maximum short circuit current is shown as $43.0 \mathrm{kA}$ on the Class $1 \mathrm{E}$ Bus and $43.5 \mathrm{kA}$ on the non-Class $1 \mathrm{E}$ Bus B as shown in Figure 3.

Nevertheless the short circuit fault scarcely occurs during the normal operation with EDG test, and the amount of the short circuit fault current, when the EDG is connected in parallel, is extremely high and necessary to reduce the fault current for the safety of nuclear power plants.

In spite of the effort to reduce the short circuit current by applying high transformer impedance, the short circuit current varies from $32.2 \mathrm{kA}$ to $43.5 \mathrm{kA}$ which depends on 
TABLE 1: The result of load flow analysis for APR1400.

\begin{tabular}{|c|c|c|c|c|c|c|}
\hline Power source & $4.16 \mathrm{kV}$ bus & Cat. I & Cat. II & Cat. III & Cat. IV & Cat. V \\
\hline \multirow{4}{*}{ UAT } & $\begin{array}{c}\text { Non-Class } \\
\text { 1E Bus A }\end{array}$ & $95.53 \%$ & $97.90 \%$ & $95.68 \%$ & $97.41 \%$ & $103.21 \%$ \\
\hline & $\begin{array}{c}\text { Non-Class } \\
\text { 1E Bus B }\end{array}$ & $95.45 \%$ & $97.76 \%$ & $95.55 \%$ & $97.30 \%$ & $102.89 \%$ \\
\hline & $\begin{array}{c}\text { Class 1E } \\
\text { Bus A }\end{array}$ & $95.45 \%$ & $97.83 \%$ & $95.48 \%$ & $97.28 \%$ & $103.21 \%$ \\
\hline & $\begin{array}{c}\text { Class 1E } \\
\text { Bus B }\end{array}$ & $95.53 \%$ & $97.90 \%$ & $95.68 \%$ & $97.41 \%$ & $103.21 \%$ \\
\hline \multirow{4}{*}{ SAT $^{*}$} & $\begin{array}{c}\text { Non-Class } \\
1 E \text { Bus A }\end{array}$ & - & $97.79 \%$ & $96.40 \%$ & $98.08 \%$ & $103.15 \%$ \\
\hline & $\begin{array}{c}\text { Non-Class } \\
\text { 1E Bus B }\end{array}$ & - & $97.70 \%$ & $96.33 \%$ & $98.02 \%$ & $102.91 \%$ \\
\hline & $\begin{array}{c}\text { Class 1E } \\
\text { Bus A }\end{array}$ & - & $97.71 \%$ & $96.20 \%$ & $97.96 \%$ & $103.15 \%$ \\
\hline & $\begin{array}{c}\text { Class 1E } \\
\text { Bus B }\end{array}$ & - & $97.79 \%$ & $96.40 \%$ & $98.08 \%$ & $103.15 \%$ \\
\hline
\end{tabular}

${ }^{*}$ During the plant start-up condition (Cat. I), the electric power system receives power only through UAT.

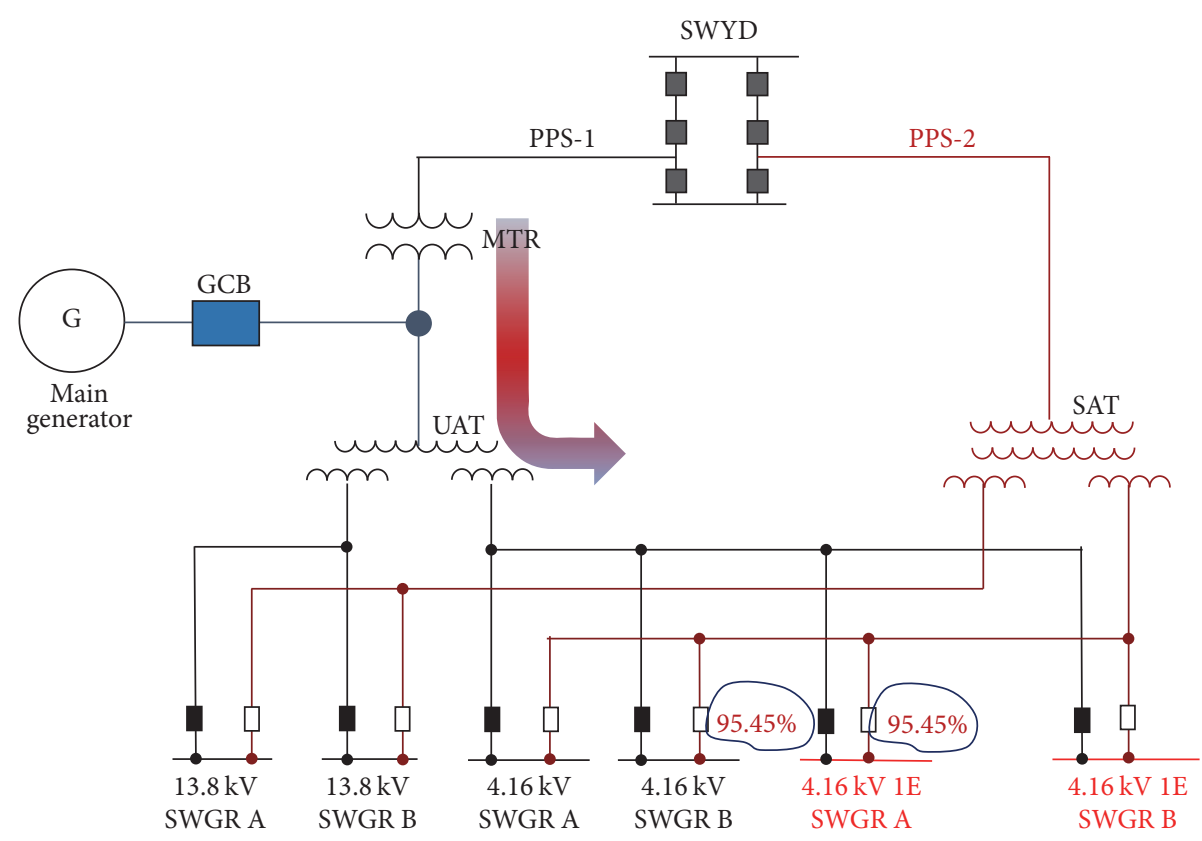

FIGURE 2: Voltage variation during the start-up condition.

the transformer impedance during each loading category as shown in Table 2.

Considering the huge short circuit current, high fault current withstand capability equipment such as circuit breakers and buses should be applied. By reason of the huge short circuit current, relatively high short circuit current withstand capability, $50 \mathrm{kA}$, is applied for the circuit breakers and buses of $4.16 \mathrm{kV}$ switchgear in APR1400.

In addition, if the transformer impedance is adjusted to minimize the high voltage drop, then the huge short circuit fault current is caused by the low transformer impedance as well. There is a great concern regarding the optimized transformer impedance adjustment in order to minimize the voltage drop and short circuit simultaneously.

2.3. Improvement of Design Vulnerability. To supply Class $1 \mathrm{E}$ power to the downstream loads connected to $480 \mathrm{~V}$ MCC, consideration of the voltage drop through cables and $480 \mathrm{~V}$ load center (LC) transformers is necessary. Due to the operating voltage limitation on $480 \mathrm{~V}$ MCC as $90 \%$ of nominal voltage especially in the severe condition during the plant start-up operation, the voltage drop should be limited in $5.45 \%$ (=95.45\% - 90\%) from $4.16 \mathrm{kV}$ Class $1 \mathrm{E}$ Bus to $480 \mathrm{~V}$ MCC loads. Therefore, massively sized cables, to reduce the 
TABLE 2: The result of short circuit current analysis for APR1400.

\begin{tabular}{|c|c|c|c|c|c|c|}
\hline Power source & $4.16 \mathrm{kV}$ bus & Cat. I & Cat. II & Cat. III & Cat. IV & Cat. V \\
\hline \multirow{4}{*}{ UAT } & $\begin{array}{c}\text { Non-Class 1E } \\
\text { Bus A }\end{array}$ & $39.1 \mathrm{kA}$ & $43.5 \mathrm{kA}$ & $42.4 \mathrm{kA}$ & $42.4 \mathrm{kA}$ & $43.5 \mathrm{kA}$ \\
\hline & $\begin{array}{c}\text { Non-Class 1E } \\
\text { Bus B }\end{array}$ & $38.2 \mathrm{kA}$ & $35.1 \mathrm{kA}$ & $37.4 \mathrm{kA}$ & $36.0 \mathrm{kA}$ & $42.0 \mathrm{kA}$ \\
\hline & $\begin{array}{c}\text { Class 1E } \\
\text { Bus A }\end{array}$ & $35.1 \mathrm{kA}$ & $32.2 \mathrm{kA}$ & $34.7 \mathrm{kA}$ & $33.3 \mathrm{kA}$ & $43.0 \mathrm{kA}$ \\
\hline & $\begin{array}{c}\text { Class 1E } \\
\text { Bus B }\end{array}$ & $36.7 \mathrm{kA}$ & $33.5 \mathrm{kA}$ & $35.7 \mathrm{kA}$ & $34.3 \mathrm{kA}$ & $43.0 \mathrm{kA}$ \\
\hline \multirow{4}{*}{ SAT $^{*}$} & $\begin{array}{c}\text { Non-Class 1E } \\
\text { Bus A }\end{array}$ & - & $42.7 \mathrm{kA}$ & $42.4 \mathrm{kA}$ & $42.4 \mathrm{kA}$ & $42.6 \mathrm{kA}$ \\
\hline & $\begin{array}{c}\text { Non-Class } 1 \mathrm{E} \\
\text { Bus B }\end{array}$ & - & $35.4 \mathrm{kA}$ & $37.9 \mathrm{kA}$ & $37.4 \mathrm{kA}$ & $42.7 \mathrm{kA}$ \\
\hline & $\begin{array}{c}\text { Class 1E } \\
\text { Bus A }\end{array}$ & - & $32.5 \mathrm{kA}$ & $36.2 \mathrm{kA}$ & $34.7 \mathrm{kA}$ & $43.0 \mathrm{kA}$ \\
\hline & $\begin{array}{c}\text { Class 1E } \\
\text { Bus B }\end{array}$ & - & $33.8 \mathrm{kA}$ & $35.0 \mathrm{kA}$ & $35.7 \mathrm{kA}$ & $43.0 \mathrm{kA}$ \\
\hline
\end{tabular}

${ }^{*}$ During the plant start-up condition (Cat. I), the electric power system receives power only through UAT.

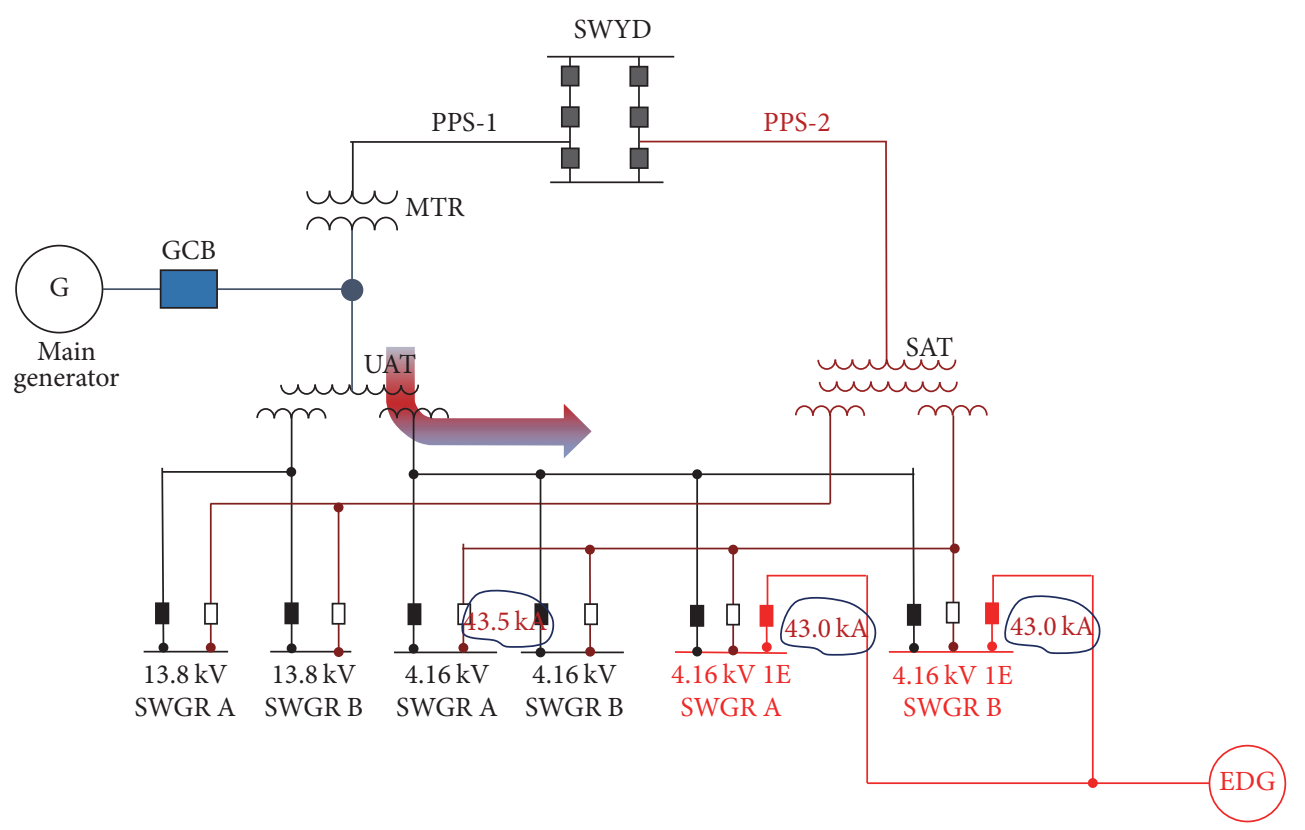

Figure 3: Short circuit current during the normal operation with EDG test.

voltage drop, were applied due to the limitation within the allowable voltage drop range. Then, if the voltage drop can be reduced, the cable size will be decreased.

On the other hand, if the short circuit current is reduced as much as possible, circuit breakers and buses can be downsized in terms of short circuit current withstand capability. If there is a likelihood of transformer impedance optimization, the voltage drop and short circuit current can be reduced. Since UAT and SAT supply power to non-Class 1E Bus and Class 1E Bus simultaneously in the existing electric power system, adjusting transformer impedance only for Class $1 \mathrm{E}$ Bus is impractical. As a result, the additional UAT and
SAT only for Class $1 \mathrm{E}$ system may be adopted so that the transformer impedance can be optimized. Also UAT and SAT for non-Class $1 \mathrm{E}$ system can be downsized, respectively. Therefore the separation of UAT and SAT is considerable.

\section{Separation of UAT and SAT}

In order to enhance the safety and reliability of Class $1 \mathrm{E}$ system, separation of UAT and SAT may be considered as demonstrated (see Figure 4).

The improved voltage regulation and limited short circuit current by separation of UAT and SAT will be clearly 


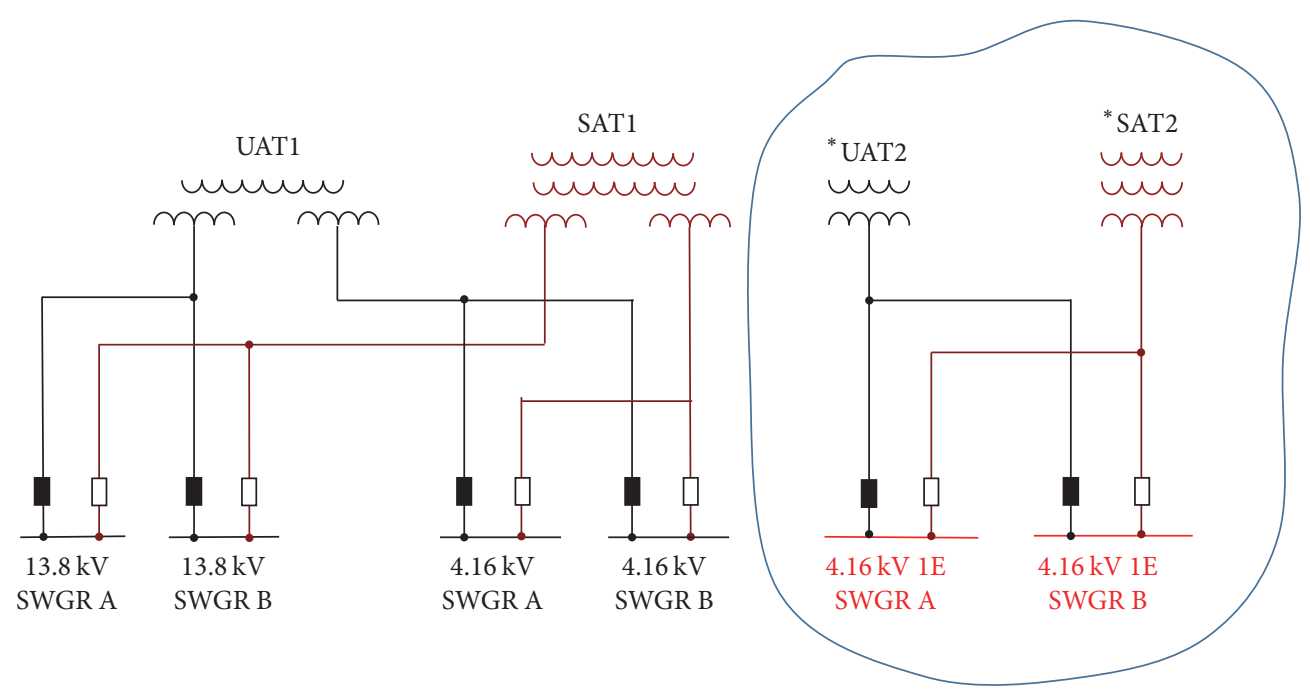

FIGURE 4: UAT and SAT separation for safety loads. * For safety loads.

TABLE 3: Apparent power rating (kVA) loading summary of Class $1 \mathrm{E}$ system.

\begin{tabular}{lcccc}
\hline \multirow{2}{*}{ Voltage level } & \multicolumn{4}{c}{ Condition (kVA) } \\
& Cat. I & Cat. II & Cat. III & Cat. IV \\
\hline $4.16 \mathrm{kV}$ & 9160 & 5616 & 9080 & 6518 \\
\hline
\end{tabular}

demonstrated through this paper. Additionally, reliability and cost are considerable issue.

3.1. Modelling of UAT and SAT Separation. The existing UAT and SAT capacities are as follows.

(i) UAT: $71 / 50 / 21 \mathrm{MVA}(\mathrm{H} / \mathrm{X} / \mathrm{Y})\left(45^{\circ} \mathrm{C}\right.$ rise $)$.

(ii) SAT: $67 / 46 / 21 \mathrm{MVA}(\mathrm{H} / \mathrm{X} / \mathrm{Y})\left(45^{\circ} \mathrm{C}\right.$ rise $)$.

First of all, to determine the modified model, the separated UAT and SAT size only for Class 1E loads (UAT2 and SAT2) shall be calculated based on typical APR1400 data. Based on the data from APR1400, the loading summary of Class $1 \mathrm{E}$ system can be determined as shown in Table 3.

As demonstrated in Table 3, maximum loading is $9160 \mathrm{kVA}$ at $4.16 \mathrm{kV}$ winding. For the consideration of future loads, $10 \%$ margin shall be applied as a minimum. $10076 \mathrm{kVA}$ $(=9160 \mathrm{kVA} \times 1.1)$ is applied for ONAF [11] $\left(45^{\circ} \mathrm{C}\right.$ rise $)$ rating.

UAT and SAT have both ONAN and ONAF rating. In order to calculate sufficient capacity for the loads, the size of transformers is first calculated as ONAF rating which has $133 \%$ of ONAN rating. As ONAN rating is representative capacity of transformers, the capacity of transformers shall be converted into ONAN rating.

Finally, $4.16 \mathrm{kV}$ Y-winding capacities $\left(45^{\circ} \mathrm{C}\right.$ rise $)$ of UAT2 and SAT2 only for Class $1 \mathrm{E}$ loads are calculated as $7558.9 \mathrm{kVA}$ (=10076 kVA/1.33).

As a result, the capacity of the separated UAT2 and SAT2 is estimated as $8000 \mathrm{kVA}$.

On the other hand, the existing UAT and SAT can be modified only for supplying power to non-Class $1 \mathrm{E}$ loads.
TABLE 4: Apparent power rating (kVA) loading summary of APR1400.

\begin{tabular}{lcccc}
\hline \multirow{2}{*}{ Voltage level } & \multicolumn{4}{c}{ Condition (kVA) } \\
& Cat. I & Cat. II & Cat. III & Cat. IV \\
\hline $13.8 \mathrm{kV}$ & 49441 & 59562 & 59624 & 59127 \\
$4.16 \mathrm{kV}$ & 23988 & 19772 & 23304 & 19390 \\
\hline
\end{tabular}

TABLE 5: Apparent power rating (kVA) loading summary only for non-Class $1 \mathrm{E}$ loads.

\begin{tabular}{lcccr}
\hline \multirow{2}{*}{ Voltage level } & \multicolumn{4}{c}{ Condition (kVA) } \\
& Cat. I & Cat. II & Cat. III & Cat. IV \\
\hline $13.8 \mathrm{kV}$ & 49441 & 59562 & 59624 & 59127 \\
$4.16 \mathrm{kV}$ & 14828 & 14157 & 14224 & 12872 \\
\hline
\end{tabular}

The existing UAT and SAT loading for Class 1E and nonClass 1E loads are shown in Table 4 and the modified UAT and SAT only for non-Class 1E loads (UAT1 and SAT1) are shown in Table 5.

As the X-winding loadings of modified UAT1 and SAT1 are not changed, the sizes of X-winding shall not be changed. The maximum loading of Y-winding is $14828 \mathrm{kVA}$ at $4.16 \mathrm{kV}$ winding. In the same manner with the calculation of UAT2 and SAT2, ONAF ratings of UAT1 and SAT1 are $16310.8 \mathrm{kVA}$. The Y-winding capacity of UAT1 and SAT1 is calculated as $12236.2 \mathrm{kVA}(=16310.8 \mathrm{kVA} / 1.33)$.

Consequently, the sizes of the modified UAT1 and SAT1 for non-Class $1 \mathrm{E}$ loads are estimated as follows.

(i) UAT1: 63/50/13 MVA (H/X/Y) $\left(45^{\circ} \mathrm{C}\right.$ rise).

(ii) SAT1: 59/46/13 MVA (H/X/Y) $\left(45^{\circ} \mathrm{C}\right.$ rise).

To apply the modified UAT and SAT size, the load flow and short circuit current analysis were done by ETAP.

3.2. Load Flow Analysis. After application of UAT and SAT separation, the voltage regulation on Class $1 \mathrm{E}$ Buses varies 
TABLE 6: The result of the modified electric power system load flow analysis.

\begin{tabular}{|c|c|c|c|c|c|c|}
\hline Power source & $4.16 \mathrm{kV}$ bus & Cat. I & Cat. II & Cat. III & Cat. IV & Cat. V \\
\hline \multirow{2}{*}{ UAT1 } & $\begin{array}{c}\text { Non-Class 1E } \\
\text { Bus A }\end{array}$ & $99.51 \%$ & $101.33 \%$ & $99.51 \%$ & $99.51 \%$ & $105.05 \%$ \\
\hline & $\begin{array}{c}\text { Non-Class 1E } \\
\text { Bus B }\end{array}$ & $100.07 \%$ & $99.00 \%$ & $100.00 \%$ & $100.00 \%$ & $99.72 \%$ \\
\hline \multirow{2}{*}{ UAT2 } & $\begin{array}{c}\text { Class 1E } \\
\text { Bus A }\end{array}$ & $99.44 \%$ & $101.25 \%$ & $99.44 \%$ & $99.44 \%$ & $105.05 \%$ \\
\hline & $\begin{array}{c}\text { Class 1E } \\
\text { Bus B }\end{array}$ & $99.51 \%$ & $101.33 \%$ & $99.51 \%$ & $99.51 \%$ & $105.05 \%$ \\
\hline \multirow{2}{*}{ SAT1 ${ }^{*}$} & $\begin{array}{c}\text { Non-Class 1E } \\
\text { Bus A }\end{array}$ & - & $100.90 \%$ & $100.90 \%$ & $100.90 \%$ & $100.00 \%$ \\
\hline & $\begin{array}{c}\text { Non-Class 1E } \\
\text { Bus B }\end{array}$ & - & $100.31 \%$ & $100.31 \%$ & $100.31 \%$ & $99.99 \%$ \\
\hline \multirow{2}{*}{ SAT2* } & $\begin{array}{c}\text { Class 1E } \\
\text { Bus A }\end{array}$ & - & $100.82 \%$ & $100.80 \%$ & $100.80 \%$ & $100.00 \%$ \\
\hline & $\begin{array}{c}\text { Class 1E } \\
\text { Bus B }\end{array}$ & - & $100.90 \%$ & $100.90 \%$ & $100.90 \%$ & $100.00 \%$ \\
\hline
\end{tabular}

${ }^{*}$ During the plant start-up condition (Cat. I), the electric power system receives power only through UAT1 and UAT2.

TABLE 7: The result of the modified electric power system short circuit current analysis.

\begin{tabular}{|c|c|c|c|c|c|c|}
\hline Power source & $4.16 \mathrm{kV}$ bus & Cat. I & Cat. II & Cat. III & Cat. IV & Cat. V \\
\hline \multirow{2}{*}{ UAT1 } & $\begin{array}{c}\text { Non-Class 1E } \\
\text { Bus A }\end{array}$ & $36.7 \mathrm{kA}$ & $40.9 \mathrm{kA}$ & $40.0 \mathrm{kA}$ & $40.0 \mathrm{kA}$ & $40.9 \mathrm{kA}$ \\
\hline & $\begin{array}{c}\text { Non-Class 1E } \\
\text { Bus B }\end{array}$ & $26.8 \mathrm{kA}$ & $26.8 \mathrm{kA}$ & $26.8 \mathrm{kA}$ & $26.8 \mathrm{kA}$ & $26.8 \mathrm{kA}$ \\
\hline \multirow{2}{*}{ UAT2 } & $\begin{array}{c}\text { Class 1E } \\
\text { Bus A }\end{array}$ & $21.7 \mathrm{kA}$ & $18.6 \mathrm{kA}$ & $21.6 \mathrm{kA}$ & $19.6 \mathrm{kA}$ & $27.3 \mathrm{kA}$ \\
\hline & $\begin{array}{c}\text { Class 1E } \\
\text { Bus B }\end{array}$ & $22.2 \mathrm{kA}$ & $18.9 \mathrm{kA}$ & $21.8 \mathrm{kA}$ & $19.8 \mathrm{kA}$ & $27.3 \mathrm{kA}$ \\
\hline \multirow{2}{*}{$\mathrm{SAT}^{*}$} & $\begin{array}{c}\text { Non-Class 1E } \\
\text { Bus A }\end{array}$ & - & $41.4 \mathrm{kA}$ & $41.1 \mathrm{kA}$ & $40.0 \mathrm{kA}$ & $41.4 \mathrm{kA}$ \\
\hline & $\begin{array}{c}\text { Non-Class 1E } \\
\text { Bus B }\end{array}$ & - & $28.1 \mathrm{kA}$ & $28.1 \mathrm{kA}$ & $26.8 \mathrm{kA}$ & $28.1 \mathrm{kA}$ \\
\hline \multirow{2}{*}{ SAT2 ${ }^{*}$} & $\begin{array}{c}\text { Class } 1 \mathrm{E} \\
\text { Bus A }\end{array}$ & - & $13.3 \mathrm{kA}$ & $16.5 \mathrm{kA}$ & $19.6 \mathrm{kA}$ & $21.6 \mathrm{kA}$ \\
\hline & $\begin{array}{c}\text { Class 1E } \\
\text { Bus B }\end{array}$ & - & $13.5 \mathrm{kA}$ & $16.5 \mathrm{kA}$ & $19.8 \mathrm{kA}$ & $21.6 \mathrm{kA}$ \\
\hline
\end{tabular}

${ }^{*}$ During the plant start-up condition (Cat. I), the electric power system receives power only through UAT1 and UAT2.

from $99.44 \%$ to $105.05 \%$ based on the same OLTC as shown in Table 6.

Due to the operating voltage limitation on $480 \mathrm{~V}$ MCC as $90 \%$ of nominal voltage during each loading category, the voltage drop should be limited in 9.44\% (=99.44\% - 90\%) from $4.16 \mathrm{kV}$ Class $1 \mathrm{E}$ Buses to $480 \mathrm{~V}$ MCC loads in the most severe condition.

Therefore, $3.99 \%(=95.45 \%-99.44 \%)$ extra margin in terms of the voltage drop between $4.16 \mathrm{kV}$ Class $1 \mathrm{E}$ Bus and $480 \mathrm{~V}$ MCC loads is obtained so that smaller size cables can be applied compared to the existing electric power system.
For degraded undervoltage relay, the margin is also increased from $0.45 \%$ to $4.44 \%$ compared to the existing electric power system.

3.3. Short Circuit Current Analysis. Through the short circuit current analysis of the modified electric power system, the fault current on Class 1E Buses varies from $13.3 \mathrm{kA}$ to $27.3 \mathrm{kA}$ as shown in Table 7 based on the following transformer impedance for Class $1 \mathrm{E}$ loads.

(i) UAT2 impedance $=7.5 \%$.

(ii) SAT2 impedance $=15 \%$. 
TABLE 8: Power transformer failures based on the components during 2009 2013.

\begin{tabular}{lcc}
\hline Failure category & $\begin{array}{c}\text { Number of failures } \\
(2009 \sim 2013)\end{array}$ & $\begin{array}{c}\text { Percentage of } \\
\text { failures }(\%)\end{array}$ \\
\hline Winding & 28 & 14.3 \\
Core & 15 & 7.7 \\
Bushing & 26 & 13.3 \\
OLTC & 20 & 10.2 \\
Tank & 6 & 3.1 \\
Coolant & 9 & 4.6 \\
Insulation & 80 & 40.8 \\
Others & 12 & 6.1 \\
\hline Total & 196 & 100 \\
\hline
\end{tabular}

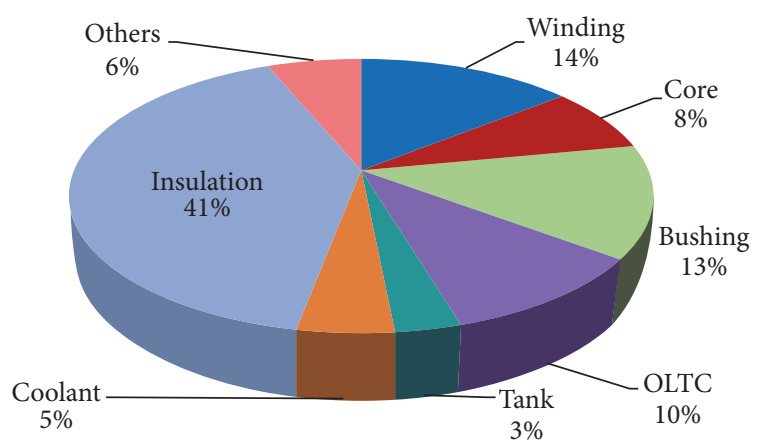

FIGURE 5: Failure statistics of power transformer component based failures.

Even though the maximum short circuit current occurs when the EDG test is done during the normal operation, the magnitude of the current is limited as $27.3 \mathrm{kA}$. By reducing the short circuit current by less than $40 \mathrm{kA}$, lower short circuit current withstand capability equipment such as circuit breakers and buses which have $40 \mathrm{kA}$ withstand capability can be applied to the Class 1E system.

3.4. Reliability Analysis. For the reliability analysis, this paper cites the recent paper [12], which stated the failure rate of power transformer during the five (5) years (2009 2013) in India (see Table 8 and Figure 5). The failures of the power transformers in order of highest to lowest frequency were insulation, winding, bushing, OLTC, core, others, coolant, and tank, respectively.

In accordance with the APR1400 data, there are several differences (bushing, winding, and core) between 2winding and 3-winding transformer in terms of assembly. Approximately, 3-winding transformer has 3 times of bushing quantity, 1.5 times of winding quantity, and 1.5 times of core quantity compared to 2 -winding transformer.

As a result, the 3-winding transformer failures were assumed as 1.37 times higher than 2-winding transformer.

According to IEEE Std. 493 [13], the failure rate of transformers is as shown below.

(i) $300 \mathrm{kVA}$ to $10000 \mathrm{kVA}=0.0059$.

(ii) Above $10000 \mathrm{kVA}=0.0153$.

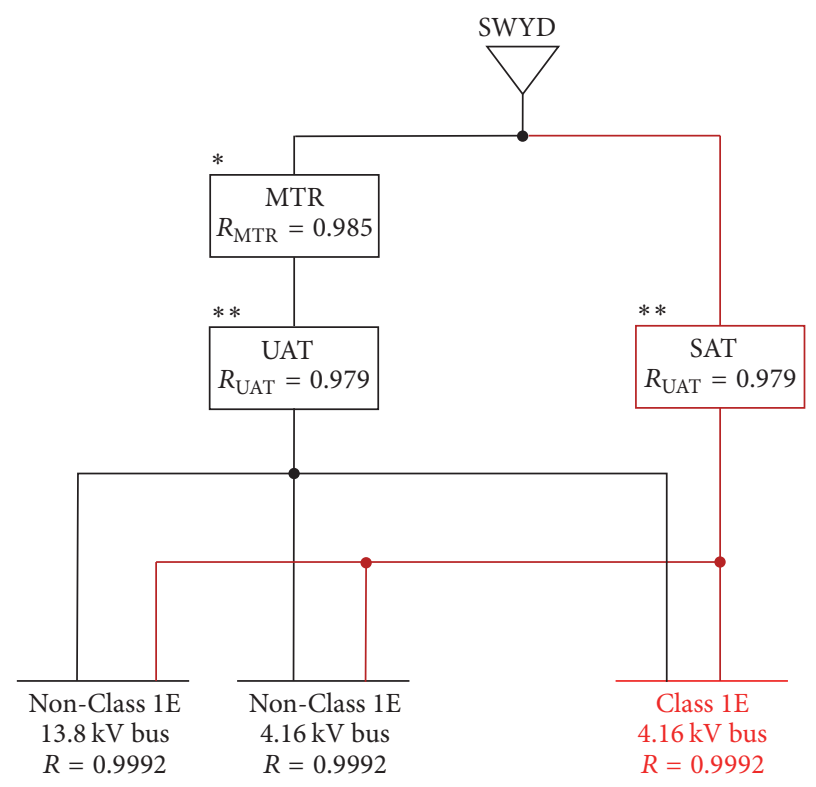

FIgURE 6: Reliability of existing electric power system. ${ }^{*}$ Twowinding transformer. ${ }^{* *}$ Three-winding transformer.

As the main transformer (MTR), UAT1 and SAT1 have capacities over $10000 \mathrm{kVA}$, and the failures of MTR, UAT1, and SAT1, $\lambda$, can be 0.0153 failures/year. Regarding the failure rate calculation of UAT, UAT1, SAT, and SAT1, the previous assumption for 3-winding transformer is used as follows:

$$
\begin{aligned}
\lambda_{\mathrm{MTR}} & =0.0153 \text { failures } / \text { year, } \\
\lambda_{\mathrm{UAT}} & =\lambda_{\mathrm{UAT} 1}=0.0153 \text { failures } / \text { year } \times 1.37 \\
& =0.0209 \text { failures } / \text { year, } \\
\lambda_{\mathrm{SAT}} & =\lambda_{\mathrm{SAT} 1}=0.0153 \text { failures } / \text { year } \times 1.37 \\
& =0.0209 \text { failures } / \text { year. }
\end{aligned}
$$

As the UAT2 and SAT2 have capacities of $8000 \mathrm{kVA}$ according to the calculated capacity of UAT2 and SAT2, the failure of UAT2 and SAT2 is 0.0059 failures/year:

$$
\lambda_{\mathrm{UAT} 2}=\lambda_{\mathrm{SAT} 2}=0.0059 \text { failures/year. }
$$

Consequently, the reliability of the electric power system can be calculated by using each failure rate:

$$
\begin{gathered}
R_{\mathrm{MTR}}=e^{-0.0153}=0.985, \\
R_{\mathrm{UAT}}=R_{\mathrm{UAT} 1}=e^{-0.0209}=0.979, \\
R_{\mathrm{SAT}}=R_{\mathrm{SAT} 1}=e^{-0.0209}=0.979, \\
R_{\mathrm{UAT} 2}=R_{\mathrm{SAT} 2}=e^{-0.0059}=0.994 .
\end{gathered}
$$

Simplifying the reliability of the modified electric power system is complicated; however, the comparison between two systems is available for the reliability analysis.

As shown in Figure 6 which was simplified and focused on the connection between transformers and buses, the 


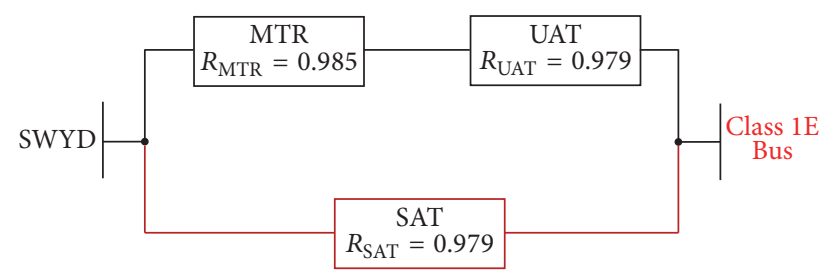

FIGURE 7: Existing electric power system reliability block diagram for Class 1E Bus.

reliability of Class 1E Bus in the existing electric power system is estimated according to the reliability block diagram (see Figure 7) and following equation.

The reliability of MTR and UAT series connection is calculated according to the following equation:

$$
R_{S}=R_{1} \times R_{2},
$$

where $R_{S}$ is total reliability of a series connection and $R_{1}$ and $R_{2}$ are unit reliability in a series connection. $R_{\mathrm{MTR}}$ and $R_{\mathrm{UAT}}$ are considered as unit reliabilities $R_{1}$ and $R_{2}$, respectively. $R_{S}$ is calculated as $0.964(=0.985 \times 0.979)$ by using $(4)$ :

$$
R_{P}=1-\left(1-R_{3}\right)\left(1-R_{4}\right),
$$

where $R_{P}$ is total reliability of a parallel connection and $R_{3}$ and $R_{4}$ are unit reliability in a parallel connection. Previously calculated $R_{S}$ and $R_{\mathrm{SAT}}$ are considered as $R_{3}$ and $R_{4}$, respectively, for parallel connection calculation. $R_{P}$ is calculated as $0.9992(=1-(1-0.964)(1-0.979))$ by using (5).

Therefore, the total reliability of Class $1 \mathrm{E}$ Bus is 0.9992 .

As shown in Figure 8, the reliability of Class 1E Bus in the modified electric power system is estimated in accordance with the reliability block diagram (see Figure 9) and calculations by using (4) and (5).

According to the calculation, the total reliability of Class $1 \mathrm{E}$ Bus in the modified system is calculated as 0.9999 .

There were no reliability decrease and failure rate increase due to the separation of UAT and SAT, but rather the reliability has increased and the failure rate has decreased, respectively.

\subsection{Cost Estimation}

3.5.1. Transformers and Vacuum Circuit Breakers. The cost of transformer is estimated by using the power factor of SWEC. SWEC in US was suggested power factor according to components types as shown in Table 9 [14].

As shown in Table 9, the power factor of transformer is 0.6 .

For the cost estimation of UAT1, SAT1, UAT2, and SAT2, the following equation is used:

$$
C_{2}=C_{1} \times\left(\frac{Q_{2}}{Q_{1}}\right)^{p},
$$

where $C_{1}$ is current plant construction cost (\$); $C_{2}$ is new plant construction cost $(\$) ; Q_{1}$ is current technical quantity

\begin{tabular}{|c|c|c|}
\hline Items & Technical quantity & $\begin{array}{c}\text { Power } \\
\text { factor }(p)\end{array}$ \\
\hline NSSS main component & Thermal power (MWt) & 0.5 \\
\hline Main turbine & Electric power (MWe) & 0.62 \\
\hline Pump & Flow rate (gpm) & 0.63 \\
\hline \multicolumn{3}{|l|}{ Tank } \\
\hline NSSS & Capacity & 0.8 \\
\hline BOP & Capacity & 0.65 \\
\hline \multicolumn{3}{|l|}{ Heat exchange } \\
\hline NSSS & Heat transfer rate & 0.5 \\
\hline BOP & Heat transfer rate & 0.51 \\
\hline Blower & Capacity (cfm) & 0.77 \\
\hline $\mathrm{AHU}, \mathrm{ACU}$ & Capacity (cfm) & 0.75 \\
\hline Air compressor & Capacity & 0.78 \\
\hline Cubicle cooler & Capacity & 0.71 \\
\hline Filter & Flow rate (gpm) & 0.62 \\
\hline Demineralizer & Flow rate (gpm) & 0.6 \\
\hline FW heater & Flow rate (gpm) & 0.55 \\
\hline Emergency D/G & Power $(\mathrm{kW})$ & 0.6 \\
\hline Chiller & Capacity (RT) & 0.74 \\
\hline Crane & Capacity (TN) & 0.6 \\
\hline Aux boiler & Capacity (b/hr) & 0.6 \\
\hline Transformer & MVA & 0.6 \\
\hline Battery & AMP & 0.6 \\
\hline Switchgear & BKR & 0.6 \\
\hline Charger & AMP & 0.6 \\
\hline
\end{tabular}
used to cost estimate, such as power level, motor horsepower,
TABLE 9: Power factor of equipment in nuclear power plant.

and weight of component; $Q_{2}$ is new technical quantity used to cost estimate; and $p$ is power factor shown in Table 9.

Approximately $\$ 1$ Mio. per each transformer is assumed for cost estimation of UAT and SAT. Therefore, the cost of each transformer is as follows:

$$
\begin{aligned}
& \text { UAT1: \$ } 1 \text { Mio. } \times\left(\frac{63 \mathrm{MVA}}{71 \mathrm{MVA}}\right)^{0.6}=\$ 0.931 \text { Mio., } \\
& \text { SAT1: \$ } 1 \text { Mio. } \times\left(\frac{59 \mathrm{MVA}}{67 \mathrm{MVA}}\right)^{0.6}=\$ 0.927 \text { Mio., } \\
& \text { UAT2: \$ } 1 \text { Mio. } \times\left(\frac{8 \mathrm{MVA}}{71 \mathrm{MVA}}\right)^{0.6}=\$ 0.270 \text { Mio., } \\
& \text { SAT2: } \$ 1 \text { Mio. } \times\left(\frac{8 \mathrm{MVA}}{67 \mathrm{MVA}}\right)^{0.6}=\$ 0.279 \text { Mio. }
\end{aligned}
$$

The cost summation of transformers is $\$ 2.407$ Mio. and the cost is increased as approximately $17 \%$ (\$ 0.407 Mio.) compared to the cost summation of current transformers.

In case of vacuum circuit breakers installed in $4.16 \mathrm{kV}$ Class $1 E$ switchgears, the short circuit current capacity can be reduced from $50 \mathrm{kA}$ to $40 \mathrm{kA}$ due to the decrease in short circuit current in Class $1 E$ system. There are 30 vacuum circuit breakers currently installed in $4.16 \mathrm{kV}$ Class $1 \mathrm{E}$ switchgears (Division I). As the cost difference between $50 \mathrm{kA}$ and $40 \mathrm{kA}$ 


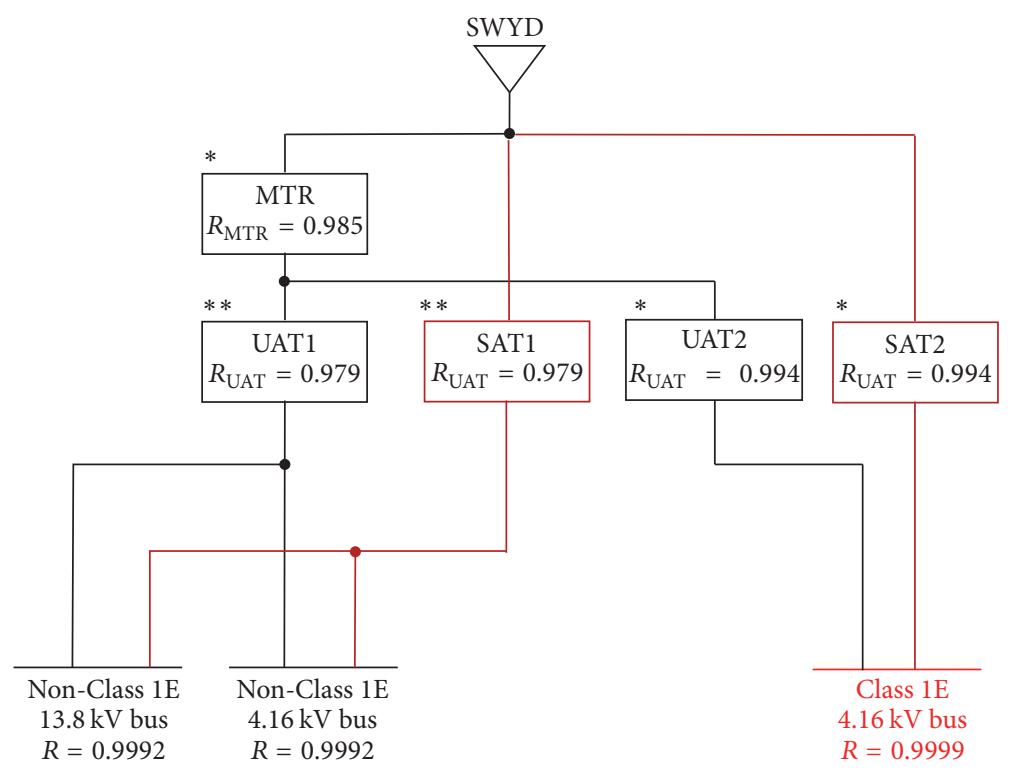

Figure 8: Reliability of modified electric power system. ${ }^{*}$ Two-winding transformer. ${ }^{* *}$ Three-winding transformer.

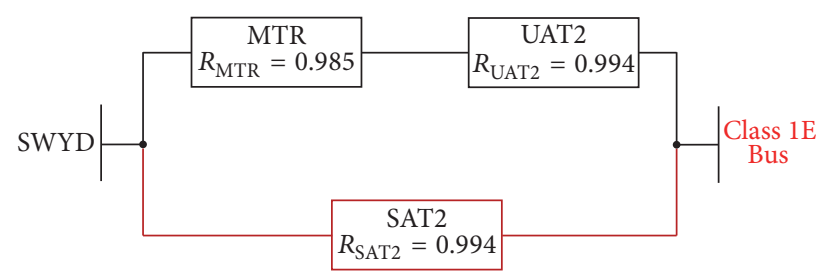

Figure 9: Modified electric power system reliability block diagram for Class 1E Bus.

is known as $\$ 8795$ per each, the total cost decrease in vacuum circuit breakers may be estimated as $\$ 0.264$ Mio.

3.5.2. Cost Impact by Reliability Changes. As discussed previously, the failure rate of UAT1, SAT1, UAT2, and SAT2 is $0.0209,0.0209,0.0059$, and 0.0059 , respectively. Furthermore, according to IEEE 493, the average replacement time of UAT1 and SAT1 is 192 hours (8 days); otherwise the average replacement time of UAT2 and SAT2 is 79.3 hours (3.3 days).

If nuclear power plant is operated for 60 years, the failure rate of each transformer is as follows:

$$
\begin{aligned}
\lambda_{\mathrm{UAT}} & =\lambda_{\mathrm{UAT} 1}=\lambda_{\mathrm{SAT}}=\lambda_{\mathrm{SAT} 1} \\
& =0.0209 \text { failures } / \text { year } \times 60 \text { years } \\
& =1.26 \text { failures } / 60 \text { years, } \\
\lambda_{\mathrm{UAT} 2} & =\lambda_{\mathrm{SAT} 2}=0.0059 \text { failures } / \text { year } \times 60 \text { years } \\
& =0.354 \text { failures } / 60 \text { years. }
\end{aligned}
$$

As the Class 1E Bus reliability is 0.9992 for the current system, the failure rate of the bus is 0.04802 failures/year. That means both UAT and SAT fail simultaneously, so that nuclear power plant is not able to deliver power to the grid.
As the current price of electricity is $\$ 0.065 / \mathrm{kWh}$ and APR1400 has 1400 MWe in Korea, the cost for plant shutdown caused by Class $1 \mathrm{E}$ unavailability is as follows:

$$
\begin{aligned}
& \$ 0.065 / \mathrm{kWh} \times 1400000 \mathrm{kWh} \times 192 \text { hours } \\
& \quad \times 2.88 \text { failures } / 60 \text { years }=\$ 50.319 \text { Mio. }
\end{aligned}
$$

On the other hand, the cost can be estimated for the improved system as follows:

$$
\begin{gathered}
\$ 0.065 / \mathrm{kWh} \times 1400000 \mathrm{kWh} \times 79.3 \text { hours } \\
\times 0.36 \text { failures } / 60 \text { years }=\$ 2.598 \text { Mio } .
\end{gathered}
$$

Finally, when the separation of UAT and SAT is applied, the cost caused by nuclear power plant outage will be decreased by $\$ 47.721$ Mio.

3.5.3. The Result of Cost Estimation. While the additional transformers caused the rise in cost, the cost caused by nuclear power plant outage and decreased in short circuit current capacity of vacuum circuit breakers will be decreased. The final cost benefit due to the separation of UAT and SAT is estimated as $\$ 47.578 \mathrm{Mio}$. (The cost benefit by reduced outage + the cost benefit in vacuum circuit breakers - the increased cost by separated transformers $=\$ 47.721$ Mio. $+\$ 0.264$ Mio. - \$ 0.407 Mio.)

Therefore, the total cost will be decreased, even though UAT and SAT are separated. Furthermore, there are much more possible benefits to be further considered in terms of cost analysis.

(i) Smaller cables can be applied through whole Class $1 \mathrm{E}$ system.

(ii) Short circuit current withstand capability of $4.16 \mathrm{kV}$ buses can be reduced. 
TABLE 10: Variance in voltage during the plant start-up condition (Cat. I).

\begin{tabular}{lcccc}
\hline \multirow{2}{*}{ Power source } & $4.16 \mathrm{kV}$ bus & \multicolumn{3}{c}{ Voltage regulation (\%) } \\
& Was & Is & Variance (\%) \\
\hline & $\begin{array}{c}\text { Class 1E } \\
\text { Bus A }\end{array}$ & 95.45 & 99.44 & 3.99 \\
& Class 1E & 95.53 & 99.51 & 3.98 \\
UAT & $\begin{array}{l}\text { Bus B } \\
\text { Non-Class 1E } \\
\text { Bus A }\end{array}$ & 99.53 & 99.51 & 3.98 \\
& $\begin{array}{c}\text { Non-Class 1E } \\
\text { Bus B }\end{array}$ & 95.45 & 100.07 & 4.62 \\
\hline
\end{tabular}

TABLE 11: Variance in short circuit current during the normal operation with EDG test condition (Cat. V).

(a) Normal operation powered via UAT

\begin{tabular}{lcccc}
\hline \multirow{2}{*}{ Power source } & \multirow{2}{*}{$4.16 \mathrm{kV}$ bus } & \multicolumn{3}{c}{ Short circuit current (kA) } \\
& Was & Is & Variance (kA) \\
\hline & Class 1E & 43.0 & 27.3 & -15.7 \\
Bus A & & & \\
Class 1E & 43.0 & 27.3 & -15.7 \\
UAT & $\begin{array}{c}\text { Bus B } \\
\text { Non-Class 1E }\end{array}$ & 43.5 & 40.9 & -2.6 \\
Bus A & & & \\
Non-Class 1E & 42.0 & 26.8 & -15.2 \\
Bus B & & & \\
\hline
\end{tabular}

(b) Normal operation powered via SAT

\begin{tabular}{lcccc}
\hline \multirow{2}{*}{ Power source } & \multirow{2}{*}{$4.16 \mathrm{kV}$ bus } & \multicolumn{3}{c}{ Short circuit current (kA) } \\
& & Was & Is & Variance (kA) \\
\hline & Class 1E & 43.0 & 21.6 & -21.4 \\
Bus A & & & \\
Class 1E & 43.0 & 21.6 & -21.4 \\
SAT & Bus B & & & -1.2 \\
& $\begin{array}{c}\text { Non-Class 1E } \\
\text { Bus A }\end{array}$ & 42.6 & 41.4 & \\
& $\begin{array}{c}\text { Non-Class 1E } \\
\text { Bus B }\end{array}$ & 42.7 & 28.1 & -14.6 \\
\hline
\end{tabular}

(iii) Short circuit current capacity of air circuit breakers in load centers and molded circuit breakers in MCC can be reduced.

3.6. Comparison of APR1400 and Improved Model. Through this paper, a comparison of the existing electric power system with the improved model was attained in terms of voltage regulation, short circuit fault current, reliability, and cost.

Based on the severe condition of the voltage regulation and short circuit fault current during the plant start-up and normal operation with the EDG test loading category, the variation of voltage regulation and short circuit current is displayed in Tables 10 and 11.
Consequently, the voltage regulation has been improved by $3.98 \% \sim 4.62 \%$ that has extremely stable range of 99.44\% 100.07\% during the plant start-up condition which is the most severe condition. In addition, the short circuit fault current has been generally decreased by $1.2 \mathrm{kA} \sim 21.4 \mathrm{kA}$ that has a relatively low range of $21.6 \mathrm{kA} \sim 41.4 \mathrm{kA}$ during the normal operation with EDG test condition which is the most severe condition as well.

(i) The voltage regulation for Class $1 E$ varies from 99.44 to $99.51 \%$ in the most severe condition.

(ii) The short circuit current for Class $1 \mathrm{E}$ varies from 21.6 to $27.3 \mathrm{kA}$ in the most severe condition.

Reliability of Class 1E Bus has been increased from 0.9992 to 0.9999 as well. Even though the cost of modified system may increase because of the additional separated UAT and SAT, the cost caused by unplanned nuclear power plant outage and decreased in short circuit current capacity of vacuum circuit breakers will be decreased. Furthermore, more advantages for modification in cost are considerable as follows:

(i) Decrease in the fault current withstand of air circuit breakers, molded case circuit breakers, and buses for Class 1E system.

(ii) Decrease in the cable size of Class $1 E$ system due to the optimized voltage regulation.

\section{Conclusion}

As discussed previously, in order to improve the design vulnerability and reliability of nuclear power plants, the separation of UAT and SAT had been considered through the present paper so that the abnormal conditions such as voltage drop and short circuit fault current are mitigated.

As a result, the voltage regulation has been improved and has a stable range during every loading category. Moreover, the short circuit fault current has been mitigated and has lower ranges. The reliability of Class $1 \mathrm{E}$ system has been improved as well. Finally, the design vulnerability and reliability of Class $1 \mathrm{E}$ system have been improved by separation of UAT and SAT as follows:

(i) Safety distribution systems which will not be affected by non-Class $1 \mathrm{E}$ distribution systems.

(ii) Any failure of UAT and SAT Y-winding which will not impact Class 1E systems.

(iii) Assurance of the better voltage regulation.

(iv) Assurance of the limited lower short circuit current.

(v) Decrease in the cable size from Class 1E Buses to downstream loads.

(vi) Decrease in the short circuit current withstand capabilities of circuit breakers and buses in Class $1 \mathrm{E}$ system.

Consequently, the safety and reliability enhancement of Class 1E system are feasible by separation of UAT and SAT. 
The further detail cost consideration of air circuit breakers, molded case circuit breakers, buses, and cables is required at the detail design stage, if the suggested electric power system will be applied in the future within the field.

\section{Competing Interests}

The authors declare that there is no conflict of interests regarding the publication of this paper.

\section{Acknowledgments}

This research was supported by the 2016 Research Fund of the KEPCO International Nuclear Graduate School (KINGS), Republic of Korea.

\section{References}

[1] IEEE, "IEEE standard criteria for class $1 \mathrm{E}$ power systems for nuclear power generating stations," IEEE 308, 2012.

[2] J.-H. Shin, S.-C. Nam, J.-G. Lee, S.-M. Baek, J.-Y. Song, and T.K. Kim, "A study on the impact of the impedance change of $345[\mathrm{kV}]$ power transformers on overall system performance," Journal of the Korean Institute of Illuminating and Electrical Installation Engineers, vol. 25, no. 8, pp. 140-149, 2011.

[3] D. C. Ra and D. M. Kim, "The study on improvement of impedance management in distribution transformers," in Proceedings of the Korean Institute of Electrical Engineers Summer Annual Conference, pp. 410-411, July 2008.

[4] H.-C. Lee, G.-J. Lee, S.-D. Hwang, and O.-B. Hyun, "An analytical study on the Effect of High impedance Transformer to reduce Distribution Fault Current," in Proceedings of the Korean Institute of Electrical Engineers Summer Annual Conference, pp. 239-240, July 2009.

[5] A. Ahmad, I. Javed, W. Nazar, and M. A. Mukhtar, "Short circuit stress analysis using FEM in power transformer on $\mathrm{H}-\mathrm{V}$ winding displaced vertically \& horizontally," Alexandria Engineering Journal, 2016.

[6] V. A. Lavrinovich, A. V. Mytnikov, and H. Li, "Advanced technology of transformer winding condition control based on nanosecond probing impulse," Resource-Efficient Technologies, vol. 2, no. 3, pp. 111-117, 2016.

[7] U. Parikh and B. R. Bhalja, "Mitigation of magnetic inrush current during controlled energization of coupled un-loaded power transformers in presence of residual flux without load side voltage measurements," International Journal of Electrical Power \& Energy Systems, vol. 76, pp. 156-164, 2016.

[8] K. SangHak, Review of inner system configuration and protection for nuclear power plant [M.S. thesis], 2011.

[9] S. Kim and W. Jeong, "Introduction of electrical system simulation and analysis used in Korean nuclear power plants," in Proceedings of the Nuclear Energy Agency ROBELSYS Workshop ADD1, pp. 56-68, March 2015.

[10] U.S. NRC Regulation title 10, Code of Federal Regulations Part 50, Domestic Licensing of Production and Utilization Facilities; Appendix A-General Design Criteria for Nuclear Power Plants, http://www.nrc.gov/reading-rm/doc-collections/cfr/part050/ part050-appa.html.

[11] "IEEE standard for general requirements for liquid-immersed distribution, power, and regulating transformers," Tech. Rep. IEEE C57.12.00, 2010.
[12] R. Murugan and R. Ramasamy, "Failure analysis of power transformer for effective maintenance planning in electric utilities," Engineering Failure Analysis, vol. 55, pp. 182-192, 2015.

[13] IEEE, "IEEE recommended practice for the design of reliable industrial and commercial power systems," IEEE 493, 2007.

[14] G.-H. Ha, "A cost scale factor according to NPP's power capacity up and down," in Proceedings of the Transactions of the Korean Nuclear Society Autumn Meeting, pp. 1-2, November 2006. 

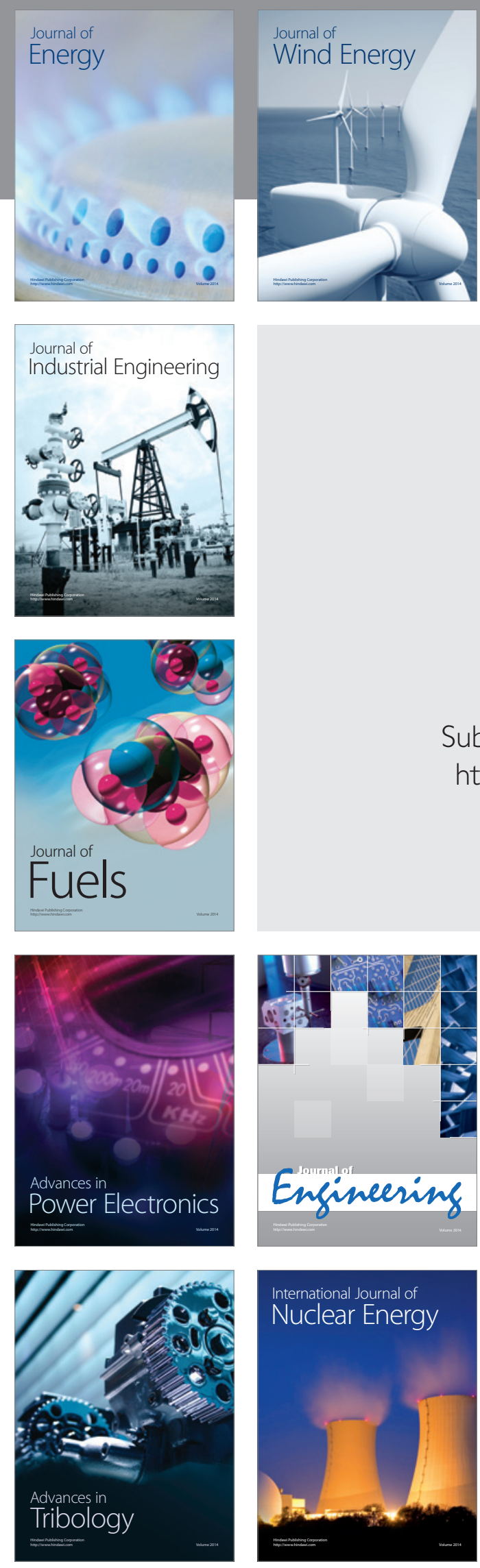

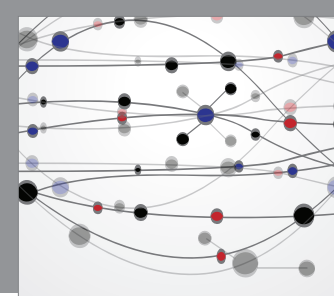

The Scientific World Journal
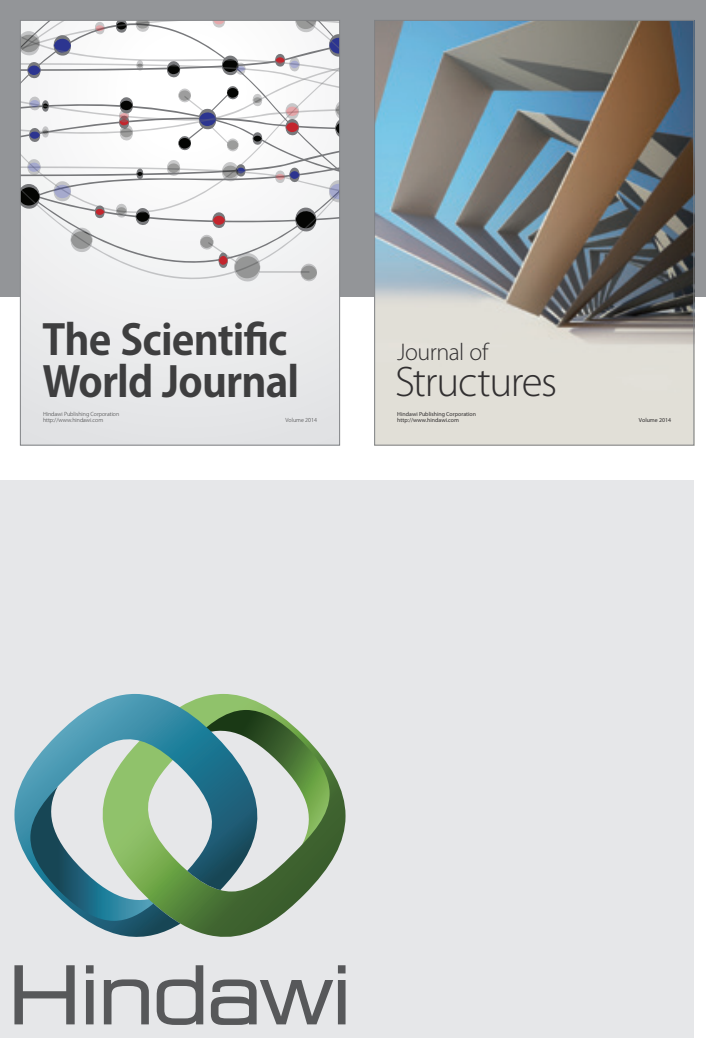

Submit your manuscripts at

https://www.hindawi.com
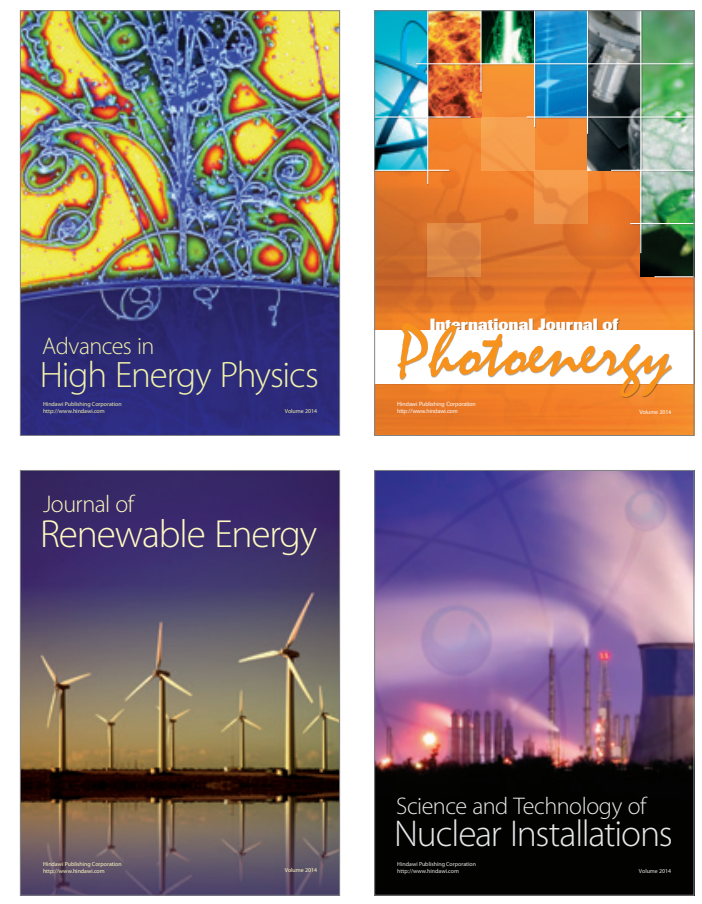
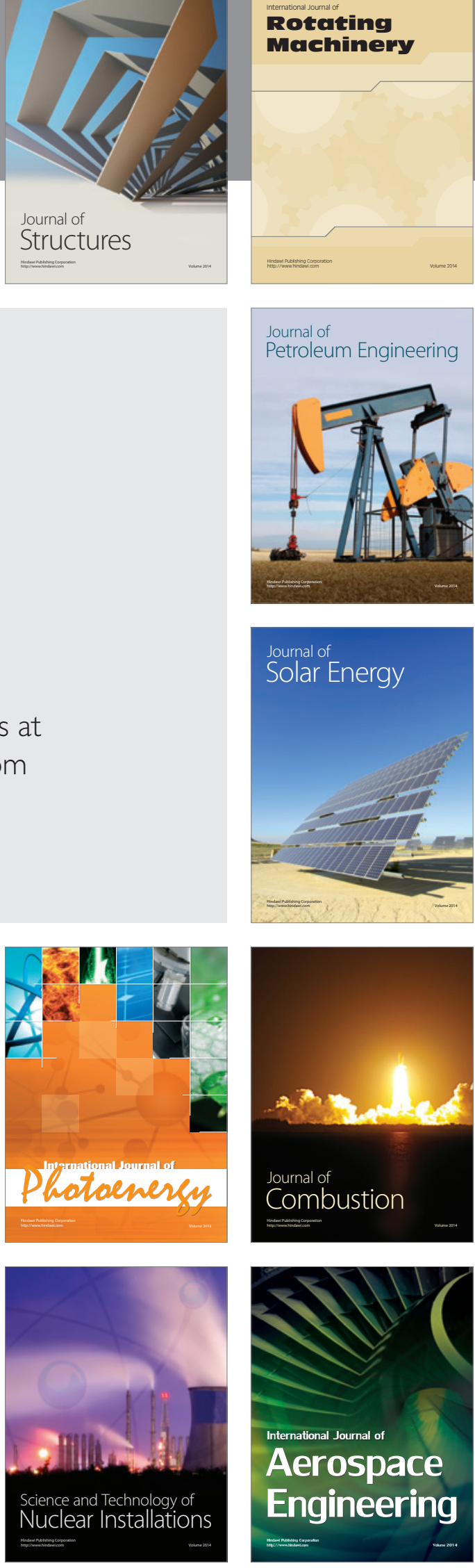